\title{
Self-Fulfilling Recessions at the Zero
}

\section{Lower Bound*}

\author{
Charles Brendon ${ }^{\dagger} \quad$ Matthias Paustian ${ }^{\ddagger} \quad$ Tony Yates
}

March 19, 2019

\begin{abstract}
We highlight an overlooked source of equilibrium multiplicity in monetary economies subject to a zero bound on nominal interest rates. In environments with sufficient endogenous propagation, depressed contemporary economic conditions must directly lower expectations of future output and inflation. A current recession followed by gradual convergence back to steady state may then be an equilibrium outcome, without any exogenous impulse. We present this mechanism heuristically in partial equilibrium, and in two computed examples of New Keynesian economies. Expansionary fiscal policy makes the recessionary equilibrium more severe at the margin, but commitment to a sufficiently large expansion can rule out multiplicity.
\end{abstract}

\footnotetext{
*The analysis and conclusions set forth in this paper are those of the authors and do not indicate concurrence by other members of the research staff or the Federal Reserve Board of Governors. We thank seminar participants at Cambridge and Surrey for helpful feedback. We are grateful to three anonymous referees and, in particular, the editor Ricardo Reis for pushing us to increase significantly the quality and ambition of the paper. All errors are ours.

${ }^{\dagger}$ Corresponding author. Address: Faculty of Economics, University of Cambridge, Cambridge CB3 9DD, UK. Email: cfb46@cam.ac.uk

${ }_{\ddagger}^{\ddagger}$ Federal Reserve Board of Governors, Washington DC
} 


\section{Introduction}

Understanding the precise implications of the zero lower bound (ZLB) constraint for macroeconomic dynamics has been an important priority for research in the recent, post-crisis decade. The resulting literature has provided extensive lessons regarding the optimal policy response to liquidity traps, as well as conflicting perspectives on the effectiveness of fiscal policy and the implications of supply shocks at the zero bound. Yet some implications of the ZLB remain under-explored. The purpose of the current paper is to identify and analyse an overlooked risk of non-fundamental recessions that can arise because of the zero bound, and to place these in the context of existing debates.

The specific issue that we identify is that a strong structural link between contemporary and future economic conditions - through the economy's endogenous propagation mechanism - can give rise to non-fundamental recessions. Suppose that a contraction in output in the current period directly implies lower future output and inflation. Under rational expectations, this link will be anticipated. If there is a limit to how far nominal interest rates can be cut, the anticipation of future stagnation, together with low or negative future inflation, may be sufficient for a collapse in current output to be an equilibrium outcome.

This dynamic is reminiscent of, but distinct from, the well-known deflationary traps highlighted by Benhabib, Schmitt-Grohé and Uribe (2001), and developed more recently by Mertens and Ravn (2014) and Aruoba et al. (2018) among others. In these authors' work, the economy becomes trapped in an inefficient equilibrium in the present, because of pessimistic expectations for the future. Agents anticipate low future inflation and output, at least probabilistically, and this depresses their current demand. With the nominal interest rate constrained at zero, the policymaker is powerless to provide stimulus. A low-output equilibrium is sustained, until some non-fundamental shock recalibrates expectations to a more benign outlook. ${ }^{1}$

\footnotetext{
${ }^{1}$ More specifically, 'sentiment' is an exogenous random variable in Mertens and Ravn (2014) and Aruoba et al. (2018). A state of pessimism must be sufficiently persistent for the deflationary trap construct to work. Benhabib et al. (2001) used a perfect-foresight approach, equivalent to pessimism persisting with probability one.
} 
An important lesson from this deflationary trap literature, therefore, is that economic performance could be improved by a concerted effort to coordinate expectations on more positive future outcomes. This is the key policy lesson drawn by Uribe (2018), for instance. Depressed conditions arise because there is a belief they will persist. If perfect foresight is assumed, convergence can only be to a low-output steady state.

Our paper studies a separate problem. When the economy contains a non-trivial endogenous propagation mechanism, any rational beliefs about future outcomes must be sensitive to current economic developments, regardless whether expectations as a whole encode optimism or pessimism. Even when beliefs are consistent with certain convergence to a non-deflationary steady state in the future, for all inherited conditions, this sensitivity itself opens the door to multiple current possibilities. A current recession must worsen expectations about future outcomes because of the endogenous propagation dynamic. In itself this will serve to incentivise saving, and reduce aggregate demand. When the propagation mechanism is sufficiently strong, this channel is enough to support the current recession. The zero bound is important to the construct, because it rules out cuts to nominal interest rates that would otherwise counteract the process.

The bulk of our paper is concerned with exploring the conditions under which this form of multiplicity may arise, and the equilibrium dynamics that it implies. As with many analyses of outcomes at the zero bound, the main intuition can be communicated by reference to the consumption Euler equation. This is the purpose of Section 2, which presents a stylised within-period equilibrium problem, assuming a given - not necessarily rational - mapping from current to expected future outcomes. This provides some simple analytical results that can help make sense of the computed examples that follow later in the paper, where expectations are fully rational.

Having established the foundations for our multiplicity problem, Section 3 then provides a first simulated example, with the multiplicity arising in a fully-specified, recursive rational expectations equilibrium. The setting is a nonlinear version of the canonical dynamic New Keynesian model, with Rotemberg pricing. The only significant departure from convention 
is to assume that the monetary policymaker feeds back aggressively on real GDP growth, in addition to inflation. This is a deliberately direct way to impart the necessary persistence into the well-studied New Keynesian environment. It allows a particularly simple form of recessionary equilibrium to arise without any exogenous impulse. This lasts for just one period, and the recession dynamics are independent of the initial state. Intuitively, a fall in output in the present period generates expectations of a relatively tight monetary policy in the future, as growth will be positive along the recovery. This means that future inflation and output expectations are rationally a function of current output. A sufficiently large fall in current output can worsen expectations so that the incentives to save rise by enough to support the low-output equilibrium.

Building on the intuition provided in Section 2, we show that the multiplicity problem can be interpreted by reference to an equilibrium Euler equation that has two solutions. This graphical representation, and the simplicity of the environment, are particularly helpful for understanding comparative statics when standard policy experiments are conducted. To this end, in Section 4 we show that conditional on a recession occurring, committing to small increases in government expenditure when the zero bound binds will always make our recessionary equilibria more severe. That is, the marginal fiscal multiplier is negative, conditional on the recessionary equilibrium being chosen. Yet we also show that commitment to a sufficiently large fiscal expansion at the zero bound is sufficient to eliminate the recessionary equilibrium. Thus our equilibria provide a qualified case for credible commitment to fiscal intervention at the zero bound, so long as the promised intervention is substantial.

Section 5 provides a second example of the multiplicity problem, in a version of the standard New Keynesian model with consumption habits and shocks to labour productivity. Here, lagged consumption is the source of persistence. A reduction in consumption in the current period reduces the marginal value of consuming in the future. This implies that future aggregate demand will be relatively low, reducing expected inflation and output.

Again, this endogenous link between current outcomes and expectations can result in two current equilibria arising, and we chart the corresponding policy functions. An interesting 
feature of multiplicity in this case, however, is that it is only arises when the economy is already relatively depressed, and operates at the zero bound whichever equilibrium is chosen. The two distinct equilibria then correspond to two distinct exit paths from an existing zero bound episode. The low-output equilibrium involves a deeper recession and a longer stay at the zero bound. In this regard we provide novel support for Blanchard's (2014) assertion that economies close to the 'dark corners', where the zero bound binds, may behave quite differently - and more unpredictably - than those in more conventional territory.

To justify the possibility that the initial consumption level may be low, we augment the setup with a stochastic process for technology. This additionally allows us to place our results in the context of the well-publicised 'paradox of toil' that can arise at the zero bound. As emphasised by Eggertsson (2010), it is possible for a persistent increase in households' marginal willingness to work to be contractionary at the zero bound in a New Keynesian model, because of the negative impact it has on future marginal costs, and hence inflation expectations. An isomorphic result arises for a positive productivity shock. More recent work by Boneva, Braun and Waki (2016) has cast doubt on the relevance of this result, arguing that it only arises in a relatively small region of the possible parameter space. Wieland (2018) provides further grounds for scepticism, based on empirical analyses of supply shocks at the zero bound.

Consistent with this, the model of Section 5 predicts that productivity improvements can be recessionary even when a conventional equilibrium is selected, but only for a very small region of the state space. Equilibrium multiplicity exists, by contrast, across a much greater region. In the multiplicity region, a positive productivity shock may be either expansionary or contractionary, depending on equilibrium selection. Taken as a whole, these results suggest that recessionary productivity improvements may be more likely than the most recent contributions have suggested, but as the product of a coordination failure rather than an economic inevitability at the zero lower bound.

Before concluding, we use Section 6 to provide a more formal discussion of the difference between our multiplicity problem and more the conventional liquidity traps in the spirit 
of Benhabib et al. (2001). We emphasise here the difference between multiplicity in the set of possible rational expectations mappings, and multiplicity that exists even when the expectations mapping is fixed. As we explain, one feature of our equilibria is that they remain possible even after learning dynamics have generated convergence in expectations to a mapping that is consistent with the non-deflationary steady state. ${ }^{2}$

\section{Partial equilibrium intuition}

The main intuition behind our results can be understood by considering a within-period consumption-savings equilibrium problem, assuming - for now - an exogenous mapping from current to expected future outcomes. The message is simplified by giving this mapping an analytical form, though clearly this convenience will not usually be available in a full rational expectations solution. In the fully solved examples of Sections 3 and 5, we will show that the qualitative properties of equilibrium expectations match those that are assumed here.

\subsection{Setup}

We consider equilibrium within some period $t$ for a simple dynamic economy where a representative consumer is choosing between consumption and savings. There is no investment and no government, so consumption is the only source of aggregate expenditure. Consumption preferences are isoelastic, and equilibrium thus requires a standard Euler condition to be satisfied in period $t$ :

$$
Y_{t}^{-\sigma}=\beta\left(1+i_{t}\right) \tilde{\mathbb{E}}_{t}\left[Y_{t+1}^{-\sigma} \Pi_{t+1}^{-1}\right]
$$

where $\tilde{\mathbb{E}}_{t}$ denotes the consumer's expectations operator, $Y_{t}$ is aggregate output in $t, \Pi_{t+1}$ is gross inflation at $t+1, \beta$ is the household's discount factor, and $\sigma$ is the inverse EIS.

\footnotetext{
${ }^{2}$ The issue of learning, and whether expectations might converge to the low-output equilibrium, remains central to debates in the liquidity trap literature. Arifovic et al. (2018) is a recent contribution challenging conventional results. See also the useful discussion in Mertens and Ravn (2014).
} 

but the most important feature is that the perceived marginal value of savings, which (3) captures, is increasing as $Y_{t}$ falls.

With this expectations mapping, the Euler condition becomes a restriction on period- $t$

${ }^{3}$ This form lacks the conventional inflation feedback term of a Taylor-type rule, again to avoid complicating the analysis with a process to determine current inflation. Alternatively, the output feedback term can be interpreted as subsuming inflation feedback, after $\Pi_{t}$ has been eliminated via the supply relation. 
outcomes alone:

$$
Y_{t}^{-\sigma}=\beta\left(1+i_{t}\right) Y_{t}^{-(\sigma \rho+\delta)}
$$

\subsection{Equilibrium multiplicity}

An equilibrium in period $t$ is a value of $Y_{t}$ such that $C_{t}=Y_{t}$ is optimal for the consumer, given the expectations and nominal interest rate that $Y_{t}$ implies. Depending on the magnitude of $Y_{t}$, this equilibrium may or may not feature a binding zero bound. Combining conditions (2) and (4), the two possibilities are:

$$
\begin{array}{r}
Y_{t}^{-\sigma-\alpha+(\sigma \rho+\delta)}=1 \text { and } Y_{t}>\beta^{\frac{1}{\alpha}} \\
Y_{t}^{-\sigma+(\sigma \rho+\delta)} \cdot \beta^{-1}=1 \text { and } Y_{t} \leq \beta^{\frac{1}{\alpha}}
\end{array}
$$

In words, equilibrium requires the representative consumer's marginal rate of substitution (MRS) between consumption and savings to equal their relative cost, which is unity. The MRS is the object on the left-hand sides of equations (2) and (4). ${ }^{4}$ It gives the ratio of the marginal utility of consumption to the marginal utility of savings in $t$, as $Y_{t}$ varies.

The MRS embeds three endogenous channels. The first is the direct effect of lower $Y_{t}$ on $C_{t}$. This raises the current marginal utility of consumption, increasing the MRS as $Y_{t}$ falls.

The second channel is the impact of lower $Y_{t}$ on current nominal interest rates, so long as the zero bound does not bind. Active interest rate cuts reduce the relative marginal value of savings as $Y_{t}$ falls, increasing the MRS. Once $Y_{t}$ falls to $\beta^{\frac{1}{\alpha}}$, the zero bound binds and this channel ceases to operate.

The third channel is the indirect effect of lower $Y_{t}$ on the expected value of future resources. So long as $\sigma \rho+\delta>0$, this increases the relative marginal value of savings as $Y_{t}$ falls, causing the MRS to fall. This channel can be further subdivided into 'income' and 'substitution' components. For $\rho>0$, lower $Y_{t}$ reduces expectations of future income, reducing optimal consumption in all periods and thus increasing savings. For $\delta>0$, lower $Y_{t}$ also re-

\footnotetext{
${ }^{4}$ Note that this is continuous at the kink point $Y_{t}=\beta^{\frac{1}{\alpha}}$.
} 
duces inflation expectations, and this increases the real interest rate, generating substitution towards savings.

The three channels correspond directly to the exponents on $Y_{t}$ in (5) and (6). Their strength is given, respectively, by $-\sigma,-\alpha$, and $\sigma \rho+\delta$.

It is clear by inspection that $Y_{t}=1$ solves condition (5), and so is one possible equilibrium. Moreover, since the left-hand side of (5) is monotone in $Y_{t}$, this is the only within-period equilibrium that is consistent with the expectations in (3) so long as the zero bound does not bind. However, the absence of an interest-rate feedback channel at the zero bound means that a second, low-output equilibrium cannot be ruled out. It is easy to confirm that this occurs whenever:

$$
-\sigma-\alpha+(\sigma \rho+\delta)<0<-\sigma+(\sigma \rho+\delta)
$$

It is always possible to choose $\alpha$ large enough for the left-hand inequality here to be satisfied. The right-hand inequality will be true if and only if $\rho+\frac{\delta}{\sigma}>1$. Intuitively, this means that as $Y_{t}$ falls below the zero bound threshold $\beta^{\frac{1}{\alpha}}$, the combination of worsened income expectations (in proportion $\rho$ ) and intertemporal substitution (in proportion $\frac{\delta}{\sigma}$ ) outweigh the direct effect of lower current consumption on the relative desire to save. A low-output equilibrium becomes possible, where once more the MRS is equal to 1.

Figure 1 illustrates this possibility. It graphs the value of the MRS as income varies, for an illustrative set of parameter values. ${ }^{5}$ So long as the zero bound does not bind, reductions in output raise the relative value of current consumption versus saving: the MRS schedule is negatively sloped. But the active policy of the central bank is crucial to this. When the nominal interest rate reaches zero, the strength of the expectation channel means that further falls in output raise the relative value of saving: the MRS schedule is now positively sloped.

For our parameterization there are two equilibria where the MRS equals 1 . The first is at $Y_{t}=\bar{Y}=1$. The second is an 'undesirable' equilibrium, with $Y_{t}$ around 5 per cent below $\bar{Y}$. This outcome is accompanied by a binding zero bound on the nominal interest rate.

\footnotetext{
${ }^{5}$ Specifically, $\sigma=1, \rho=0.9, \delta=0.2, \alpha=1$ and $\beta=0.995$.
} 


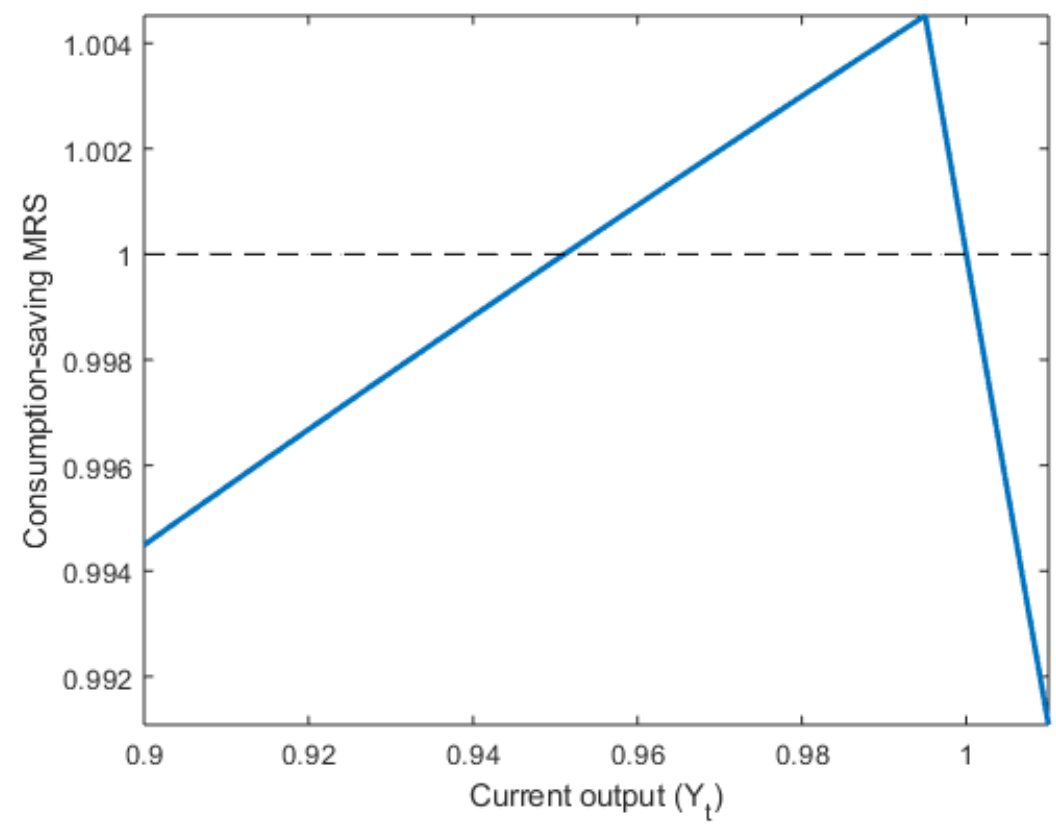

Figure 1: The value of the consumption-saving marginal rate of substitution as current output, $Y_{t}$, varies. Equilibrium obtains at the two $Y_{t}$ values where the MRS equals one.

\section{Equilibrium multiplicity in general equilibrium}

In this section we provide a first rational expectations example to illustrate how this withinperiod multiplicity problem can feature in a broader dynamic equilibrium environment.

\subsection{Overview}

The focus is on a non-linear version of the textbook New Keynesian model, deliberately chosen to minimise complexity. Our only major departure from convention is that we assume the central bank has a Taylor-style policy rule that feeds back on the growth rate of output, rather than its level. This implies that rational expectations of future outcomes must depend on current output, as modelled informally in Section 2. When the degree of policy feedback on growth is high enough, multiplicity becomes possible. The intuition is that a collapse in output in the current period implies growth back to steady state in the future. The central bank's feedback policy will therefore mandate relatively tight future monetary policy, causing consumers to expect relatively low future output and inflation rates. 
We focus on this mechanism for three reasons. The first is for ease of exposition: it is the simplest and most transparent way that we have found to illustrate our main argument in a rational expectations, general equilibrium setting. By design our mechanism requires a model with nominal rigidities, so that the zero bound matters, and where low output can occur in equilibrium because of deficient aggregate demand. The New Keynesian framework allows both of these. But our mechanism requires a non-trivial propagation mechanism, so that current and expected future outcomes are rationally linked. The standard New Keynesian model does not have this. Introducing feedback on the output gap delivers persistence directly, without adding any new components or frictions to the model.

The second reason for focusing on this mechanism is that growth feedback has been found to play a significant role in the policy rule in estimated DSGE models. The posterior mode for the growth feedback coefficient estimated for the US economy in Smets and Wouters (2007), for instance, is 1.16, compared to a feedback coefficient on the level of GDP of just 0.08. Our results suggest that growth feedback may add instability to an economy, once the zero bound is allowed for. If observed central bank behaviour is consistent with such rules being used, and if they pose a multiplicity risk, it seems important to understand this in more detail.

Finally, a number of authors have recommended growth-feedback rules as normatively desirable. Examples include Orphanides (2001, 2003), Orphanides and Williams (2002), Woodford (2003) and Blake (2012). The arguments relate both to the greater transparency of output growth relative to measures of the output gap, and dynamic commitment gains in response to markup shocks.

Overall, therefore, output growth feedback is something that seems empirically plausible as a description of how central banks do act, and has its proponents as a prescription for how they should. Given this, it is of interest to understand multiplicity problems that it may imply once the zero bound is incorporated. 


\subsection{Model setup}

We use a standard New Keynesian model without capital and with a version of Rotemberg (1982) pricing. The basic elements are presented only. A representative consumer in period $t$ chooses a consumption plan in order to maximise the discounted present value of their utility, given by:

$$
\mathbb{E}_{t} \sum_{s=t}^{\infty} \beta^{s-t}\left[\frac{C_{s}^{1-\sigma}-1}{1-\sigma}-\frac{L_{s}^{1+v}}{1+v}\right]
$$

where $L_{S}$ gives labour hours and $C_{S}$ is a standard Dixit-Stiglitz aggregate over differentiated goods $C_{s}(i)$. Government expenditure in $s, G_{s}$, is aggregated in the same way as private expenditure. The household problem gives rises to standard intertemporal and intratemporal optimality conditions:

$$
\begin{aligned}
1 & =\beta \mathbb{E}_{t}\left[\left(\frac{C_{t+1}}{C_{t}}\right)^{-\sigma} \frac{\left(1+i_{t}\right)}{\Pi_{t+1}}\right] \\
\frac{W_{t}}{P_{t}} & =\frac{L_{t}^{v}}{C_{t}^{-\sigma}}
\end{aligned}
$$

where $\Pi_{t+1}$ is the gross inflation rate in period $t+1$.

The monopolistic producer of good type $i$ employs a simple technology that is linear in labour $Y_{t}(i)=L_{t}(i)$ where $Y_{t}(i)$ is output of firm $i$ and $L_{t}(i)$ its employment. The firm chooses its price each period, subject to a convex adjustment cost, in the style of Rotemberg (1982). In particular, it chooses price $P_{t}(i)$ to maximise the discounted objective:

$$
V_{t}(i):=\mathbb{E}_{t} \sum_{s=t}^{\infty} \beta^{s-t}\left(\frac{C_{s}}{C_{t}}\right)^{-\sigma}\left\{\left[\frac{P_{S}(i)}{P_{S}}-\frac{W_{s}}{P_{S}}\right] Y_{s}(i)-\Theta\left(\frac{P_{S}(i)}{P_{S-1}(i)}\right) Y_{s}\right\}
$$

where $\Theta$ is a convex, differentiable function, with $\Theta(1)=\Theta^{\prime}(1)=0$. This cost term is multiplied by aggregate output $Y_{s}$ in period $s$, to preserve scaling. ${ }^{6}$ Taking a first-order condition

\footnotetext{
${ }^{6}$ To prevent price adjustment from having an implausible impact on aggregate activity, we model these as subjective 'as-if' losses from changing prices, rather than real resource costs. This is equivalent to the firm's objective differing from its true profit function. An identical assumption is made in Hagedorn et al. (2018) in their analysis of forward guidance. This modelling choice is irrelevant to the first-order dynamics of the model. Boneva, Braun and Waki (2016) show, however, that modelling price adjustment costs as real losses can substantially affect standard results at the zero bound when solving by global methods.
} 
for the firm's optimal pricing decision in period $t$ and imposing symmetric equilibrium gives an aggregate supply relation:

$$
0=(1-\varepsilon)+\varepsilon \frac{W_{t}}{P_{t}}-\Pi_{t} \Theta^{\prime}\left(\Pi_{t}\right)+\beta \mathbb{E}_{t}\left(\frac{C_{t+1}}{C_{t}}\right)^{-\sigma} \frac{Y_{t+1}}{Y_{t}} \Pi_{t+1} \Theta^{\prime}\left(\Pi_{t+1}\right)
$$

where $\Pi_{t}$ is the gross inflation rate in $t$. The simulations that follow set $\Theta(\Pi)=\frac{\theta}{2}[\log (\Pi)]^{2}$, where $\theta$ is a parameter capturing the size of adjustment costs. ${ }^{7}$

Aggregate market clearing will require:

$$
C_{t}+G_{t}=Y_{t}
$$

and production is linear in labor:

$$
Y_{t}=L_{t}
$$

Equations (9) to (14) provide five dynamic equilibrium conditions in the seven variables 265 $\left\{C_{t}, L_{t}, Y_{t}, \Pi_{t}, \frac{W_{t}}{P_{t}}, i_{t}, G_{t}\right\}$. A policy rule for the nominal interest rate and some specification of government expenditure, together with terminal conditions, will be sufficient to close the model. As explained above, we will assume interest rates follow a feedback rule that responds to the growth rate of output. This is the simplest way to generate the sort of multiplicity that is our focus:

$$
\left(1+i_{t}\right)=\max \left\{\beta^{-1} \Pi_{t}^{\alpha_{\pi}}\left(\frac{Y_{t}}{Y_{t-1}}\right)^{\alpha_{y}}, 1\right\}
$$

Note that this rule implicitly targets a steady-state gross inflation rate equal to 1.

For government expenditure we initially simply assume a fixed value $\bar{G}$. Section 4 considers the effects of expansionary fiscal policy at the zero bound.

\footnotetext{
${ }^{7}$ To first order this function is equivalent to the more common form $\frac{\theta}{2}[\Pi-1]^{2}$, but it has slightly more appealing global properties. It implies the cost to a firm of changing from price $P_{1}$ to $P_{2}$ is identical to the cost of changing from $P_{2}$ to $P_{1}$.
} 


\subsection{Equilibrium definition}

We will focus our attention on recursive rational expectations equilibria in this setting. These are equilibria in which expectations can be described by a time-invariant mapping from the current natural state vector only - here, just $Y_{t}$. The restrictiveness of this is to rule out dynamic paths where the outcome of within-period equilibrium selection is history-contingent, independently of $Y_{t}$. This can eliminate some interesting equilibrium possibilities, including perfect-foresight dynamics in which recessionary episodes play out over many periods.

The advantage is to keep transparent the independence of our multiplicity dynamic from persistent exogenous coordination devices.

Given the earlier distinction between multiplicity in the expectations mapping and multiplicity for a given mapping, we take some time to formalise these concepts in the current context. Equilibrium will be defined by reference to a policy function for the model's endogenous variables, and an expectations mapping. The policy function takes the form:

$$
x_{t}=g\left(Y_{t-1}, \sigma_{t}\right)
$$

where $x_{t}$ denotes the vector $\left[C_{t}, L_{t}, Y_{t}, \Pi_{t}, \frac{W_{t}}{P_{t}}, i_{t}, G_{t}\right]^{\prime}$, and $\sigma_{t}$ is a binary random variable, iid through time, that takes value 1 with probability $p$, and 0 with probability $(1-p){ }^{8}$ This is treated as a public signal, and plays the role of coordinating device between the different possibilities when more than one outcome is consistent with equilibrium. ${ }^{9}$ Specifically, a realisation $\sigma_{t}=1$ is normalised to imply coordination on the equilibrium with the lowest value for current output $Y_{t}$. If equilibrium is unique for the computed expectations mapping, then the policy function is invariant in $\sigma_{t}$. The probability $p$ will affect expectations over future outcomes, and ultimately leaves a degree of freedom in equilibrium determination. This is discussed further in Section 3.4.1.

\footnotetext{
${ }^{8}$ Where needed, subscripts identify elements of $g$ - for instance $g_{Y}\left(Y_{t-1}, \sigma_{t}\right)$ denotes the policy function for $Y$ alone.

${ }^{9} \mathrm{An}$ analogous device is used to select between outcomes in the literature on self-fulfilling crises in markets for sovereign debt - a multiplicity problem with formal similarities to ours. See Cole and Kehoe (2000).
} 


$$
\mathbb{E}_{t} f\left(x_{t+1}\right)=\phi\left(Y_{t}\right)
$$

where $f\left(x_{t+1}\right)$ stacks as a vector the set of expectations over $t+1$ outcomes relevant to equilibrium outcomes in $t$. In this case, $f\left(x_{t+1}\right)=\left[\left(C_{t+1}^{-\sigma} \Pi_{t+1}^{-1}\right),\left(C_{t+1}^{-\sigma} Y_{t+1} \Pi_{t+1} \Theta^{\prime}\left(\Pi_{t+1}\right)\right)\right]^{\prime}$, since these are the two expectational terms that feature in the model equations. Notice that expectations depend on the endogenous state vector, but not on the coordination device $\sigma_{t}$. This follows from the fact that $\sigma_{t}$ is iid over time. It highlights the feature that if there is more than one possible outcome in period $t$, this is not because of a direct shock to expectations themselves. This contrasts with the approach taken in Mertens and Ravn (2014) and Aruoba, Cuba-Borda and Schorfheide (2018), where coordination traps depend on a persistent sunspot process that shifts expectations between 'optimistic' and 'pessimistic' for any given realisation of the endogenous states.

Equilibrium requires that conditions (9) to (15) should hold for all admissible realisations of the state vector. For notational convenience let these conditions be stacked in the single vector restriction:

$$
h\left(x_{t}, \mathbb{E}_{t} f\left(x_{t+1}\right), Y_{t-1}\right)=0
$$

As is standard, we analyse outcomes on a compact state space, denoted $\mathcal{S} \subset \mathbb{R}$. A recursive rational expectations equilibrium is then defined formally as follows:

Definition. The policy function $g$, expectations mapping $\phi$ and probability $p$ are together consistent with a recursive rational expectations equilibrium if and only if for all $Y_{t-1} \in \mathcal{S}$ and $\sigma_{t} \in\{0,1\}$, the following three conditions hold:

\section{1. [Equilibrium consistency]:}

$$
h\left(g\left(Y_{t-1}, \sigma_{t}\right), \phi\left(g_{Y}\left(Y_{t-1}, \sigma_{t}\right)\right), Y_{t-1}\right)=0
$$




\begin{tabular}{|c|c|c|}
\hline Parameter & Description & Value \\
\hline \hline$\beta$ & Discount factor & $0.98^{1 / 4}$ \\
\hline$\sigma$ & Inverse EIS & 1 \\
\hline$\nu$ & Inverse Frisch & 3 \\
\hline$\varepsilon$ & Elasticity of substitution & 11 \\
\hline$\theta$ & Rotemberg cost & 30 \\
\hline$\alpha_{\pi}$ & Inflation feedback & 1.5 \\
\hline$\alpha_{y}$ & Growth feedback & 2.5 \\
\hline$\frac{G}{Y_{s s}}$ & Steady-state govt spending share & 0.25 \\
\hline
\end{tabular}

Table 1: Parameter values

2. [Rational expectations]:

$$
\phi\left(Y_{t}\right)=p f\left(g\left(Y_{t}, 1\right)\right)+(1-p) f\left(g\left(Y_{t}, 0\right)\right)
$$

3. [Boundedness]:

$$
g_{Y}\left(Y_{t-1}, \sigma_{t}\right) \in \mathcal{S}
$$

\subsection{Calibration}

Our simulations assume the following parameter values:

Most of these values are standard. The model frequency is assumed to be quarterly, so the discount factor implies roughly a 2 per cent steady-state real interest rate. A value of 30 for the Rotemberg adjustment cost parameter means that the marginal impact of higher prices on adjustment costs becomes a relevant consideration in the firm's marginal profit calculation once nominal prices are rising by around 3 per cent.

The significant non-standard choice is the value for $\alpha_{y}$, which is set to 2.5. This is higher than reported in most empirical studies, whether of the single-equation kind or based on a larger estimated DSGE model, ${ }^{10}$ but such a choice is necessary in order for the model to exhibit the self-fulfilling recessions that are our focus. As indicated by the parameter re-

\footnotetext{
${ }^{10}$ Orphanides (2003) reports values of $\alpha_{y}$ in the region of 0.5 based on single-equation estimates from post1980s US data. In their structural Bayesian analysis, Smets and Wouters (2007) find $\alpha_{y}=1.16$ at the posterior mode. This is significantly higher than the prior mean.
} 
strictions in Section 2, in order for self-fulfilling recessions to occur we need a model with either a high degree of endogenous persistence in output, or a strong link from low current

\footnotetext{
${ }^{11}$ Specifically, Mertens and Ravn (2014) show that the probability of the zero bound episode persisting must exceed around 0.6 in all periods in a standard New Keynesian setting. Our computed equilibria will exhibit time periods where the zero bound binds in $t$, but the probability of it doing so in $t+1$ is zero.
} 


\subsection{Solution method}

We solve the model by iterating on the expectations mapping $\phi$, which is projected on a grid of values for $Y$. The algorithm works as follows:

1. Initialise $\phi_{0}\left(Y^{\prime}\right)$ to the non-deflationary steady-state outcomes for $f(x)$ at all $Y^{\prime}$.

2. For all $Y$, solve for two candidate equilibrium outcomes, given the mapping $\phi_{n-1}\left(Y^{\prime}\right)$ : one in which the zero bound binds, and one in which it does not. In each case, verify that the resulting outcome is consistent with the policy rule (15) - so that if the ZLB is imposed, confirm it is indeed binding, and when it is not imposed, check that $i$ remains positive.

3. Use these two equilibrium outcomes and the exogenously specified value for $p$ to generate a new mapping $\phi_{n}(Y)$.

4. Repeat from step 2. to convergence in the $\phi$ mapping.

With a single state variable convergence is fast. We check ex-post that the equilibrium without a binding zero bound corresponds to the conventional non-deflationary New Keynesian steady state. Setting $p$ to zero guarantees this is exactly the case.

\subsection{Results}

\subsubsection{Two policy functions}

Figure 2 charts the two equilibrium policy functions that we find for aggregate income $Y_{t}$, as a function of lagged income $Y_{t-1}$. The blue function maps the case when there is coordination on a 'normal' equilibrium, with no zero bound binding. This corresponds to $g_{Y}\left(Y_{t-1}, 0\right)$ in the notation above. The green function corresponds to $g_{Y}\left(Y_{t-1}, 1\right)$ : coordination on a zero bound episode. Both functions report solutions to the model's equilibrium conditions, given an expectations mapping $\phi\left(Y_{t}\right)$ that is itself consistent with these policy functions being adopted in the future, with respective probabilities $(1-p)$ and $p$. A 45-degree line is additionally plotted, to clarify the dynamics. 


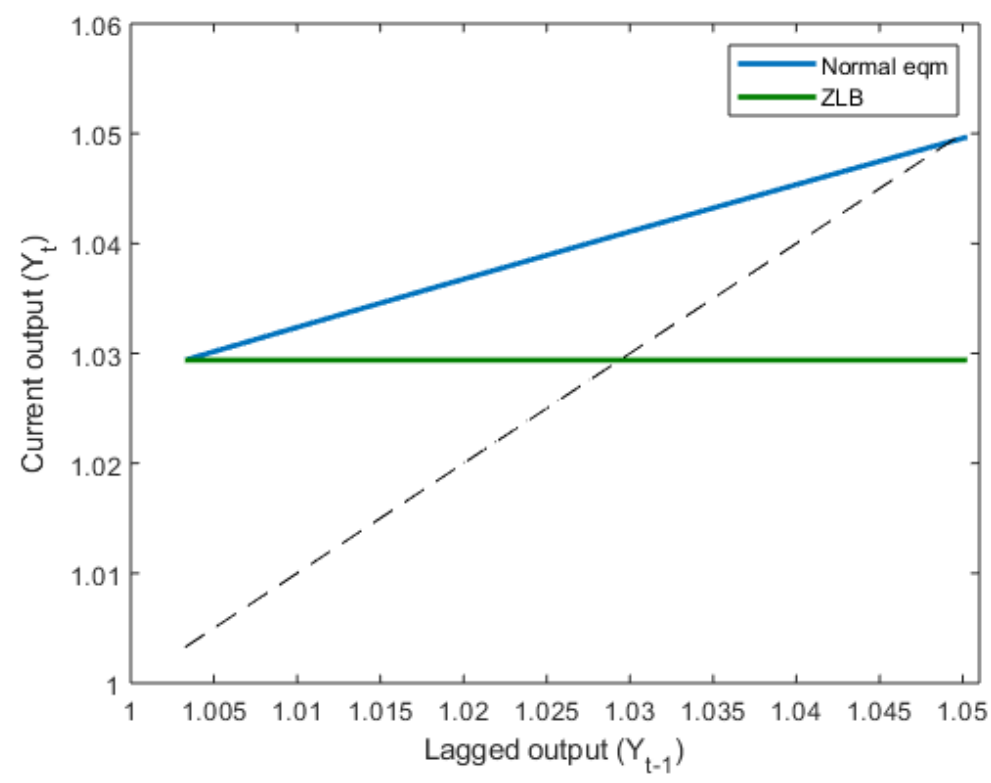

Figure 2: The two equilibrium policy functions for current output, $Y_{t}$, as a function of the state, $Y_{t-1}$. At each $Y_{t-1}$, either outcome is consistent with the model's equilibrium conditions and equilibrium expectations mapping.

The figure shows that $Y_{t}$ is an increasing function of $Y_{t-1}$ in a 'normal' equilibrium, with $\sigma_{t}=0$. This is because low values of $Y_{t-1}$ imply a higher growth rate in $t$ for any given $Y_{t}$, and this induces a contractionary monetary policy response. The zero bound does not bind in the normal equilibrium for the range charted. So long as the normal equilibrium is played in all periods, there will be straightforward convergence to a standard zero-inflation steady state for the New Keynesian model, given any initial $Y_{t-1}$ in the range shown. This steady state corresponds to the flexible-price equilibrium outcome, and differs from an efficient equilibrium only because of the market power distortion to firm pricing.

Yet even though the equilibrium expectation mapping $\phi$ effectively places unit probability on this convergence dynamic in the future, there remains a possibility that the economy will reach equilibrium at the zero bound in $t$, without any exogenous impulse. If $Y_{t}$ falls to the value given by the lower policy function, the zero bound will bind, and expectations of future economic outcomes will worsen, consistent with the equilibrium mapping $\phi\left(Y_{t}\right)$. This deterioration of expectations allows the low output level to be consistent with equilibrium in the savings market. 
Note that the level of output attained in the zero-bound equilibrium is independent of the lagged value of output. This is because $Y_{t-1}$ only enters the equilibrium problem through its impact on the policy rule. The policy rule is no longer active at the zero bound, so outcomes become invariant.

\subsubsection{The marginal rate of substitution}

Figure 3 confirms that the intuition provided by the partial equilibrium analysis in Section 2 remains applicable here. It is a solved, rational expectations equivalent to Figure 1 in Section 2. The figure plots the marginal rate of substitution between consumption and saving as the current level of output $Y_{t}$ is varied, allowing for the endogenous responses of both the nominal interest rate and future equilibrium expectations to $Y_{t}$. That is, it plots the object:

$$
M R S:=\frac{C_{t}^{-\sigma}}{\beta\left(1+i_{t}\right) \mathbb{E}_{t} C_{t+1}^{-\sigma} \Pi_{t+1}^{-1}}
$$

as a function of $Y_{t}$. Recall that equilibrium requires this fraction to equal 1, so that the Euler equation holds. The objects in both numerator and denominator are allowed to respond to $Y_{t}$ : we have $C_{t}=Y_{t}-\bar{G}, i_{t}$ responds to $Y_{t}$ through the policy rule (15), ${ }^{12}$ and the expected future values in the denominator are determined from the equilibrium $\phi$ function.

The Figure again highlights the role that the zero bound plays in allowing multiplicity. As output falls below the steady-state level, the initial implication is for the relative marginal value of consumption to rise by comparison with savings. This is because lower output and the associated lower inflation both cause the central bank to cut nominal interest rates. This dominates other effects, and reduces the relative incentive to save. But once the zero bound is reached, the outcome becomes a horse race between the direct effect of lower $C_{t}$ on the marginal value of consumption, and the effect of lower current output on the marginal value of savings through the expectations channel. At the chosen calibration it is the savings channel that dominates: the line becomes upward-sloping, and this ensures the existence of

\footnotetext{
${ }^{12}$ Lagged output is set to its steady-state value. The policy rule also requires a value for $\Pi_{t}$ as an input. Given $Y_{t}$, this is inferred from the Phillips Curve relation (12).
} 


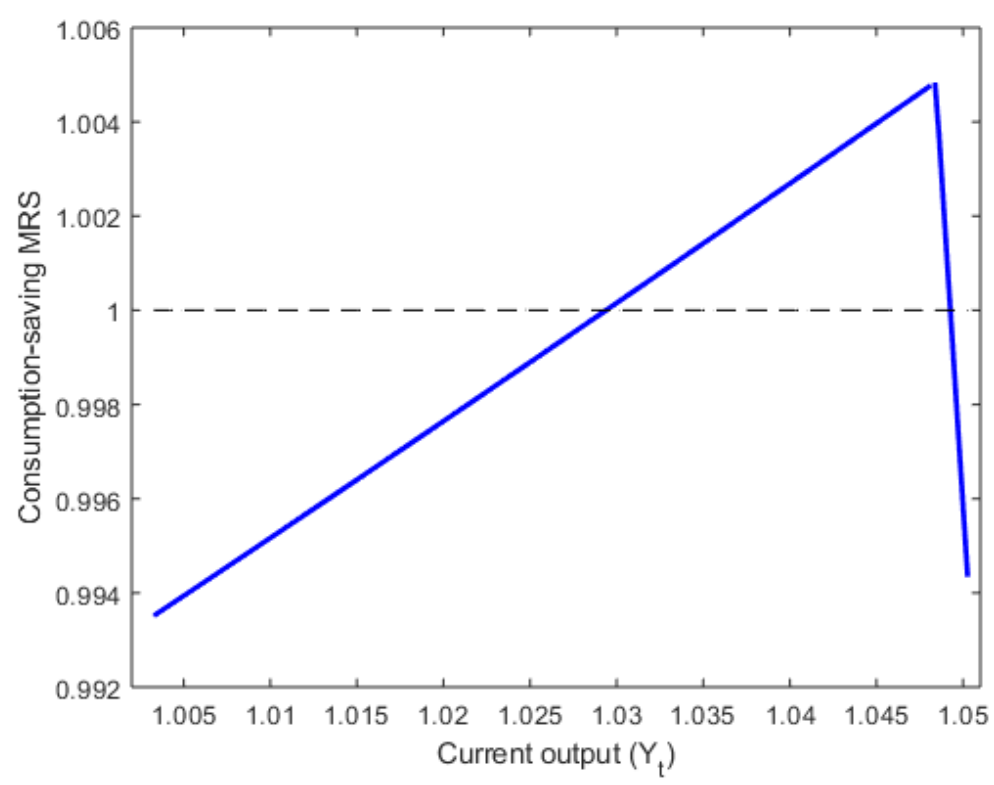

Figure 3: The marginal rate of substitution between consumption and saving as $Y_{t}$ varies. Higher values for the MRS correspond to a higher relative value placed on consumption. Equilibrium obtains at the two points where the MRS equals one.

the low-output equilibrium.

Clearly the qualitative analysis here closely mirrors that in Section 2 . The main difference is that unlike Figure 1, the expectations that give rise to Figure 3 are now fully rational, and model-consistent.

\subsubsection{A recessionary episode charted}

Figure 4 charts the dynamics of output, inflation, the expected real interest rate and the nominal interest rate during a self-fulfilling recessionary episode under the assumed parameter values. The charts are constructed by assuming the coordinating variable $\sigma_{t}$ takes an initial value of 1 followed by 0 in all periods thereafter. There is no exogenous impulse.

The general pattern is of a textbook demand-driven recession: there is a short, sharp decline in output and prices, with nominal interest rates reaching the zero bound but real rates nonetheless spiking - driven by decreased inflation expectations. Irrespective of the state vector, the economy's stay at the zero bound lasts just one period. This is a reflection of the weak propagation mechanism that is present in this model, deriving entirely from the 

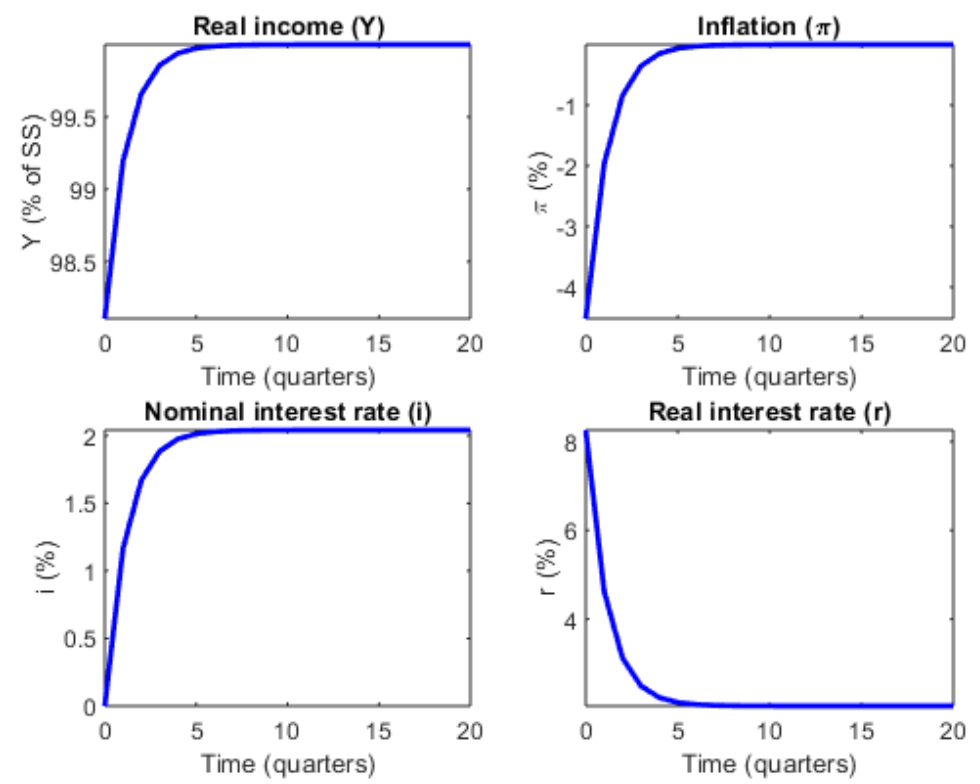

Figure 4: Impulse responses of output, inflation, and the nominal and real interest rates in a self-fulfilling recession episode. Interest rates are annualised.

lagged output term in the policy rule. In richer economies the zero bound may bind for many periods during equivalent episodes, as the case studied in Section shows.

\subsubsection{Income versus substitution channels}

The partial equilibrium example in Section 2 focused on the role of two distinct expectations effects in ensuring self-fulfilling recessions were possible. The first was an income effect: given persistence in economic conditions, a current recession implies low future earnings, and thus low current demand. The second was a substitution effect: low current output implies low future inflation, and thus a high real interest rate - again reducing current demand. In Section 2 the strength of the two channels was fixed exogenously by parametric assumptions.

In the present example a direct parametric decomposition is not possible, because expectations do not have an explicit solution. But it is possible to provide a quantification of the two effects along similar lines. Consider again the Euler condition, which can be written as:

$$
C_{t}=\left[\beta\left(1+i_{t}\right)\right]^{-\frac{1}{\sigma}}\left[\mathbb{E}_{t}\left[C_{t+1}^{-\sigma} \Pi_{t+1}^{-1}\right]\right]^{-\frac{1}{\sigma}}
$$


The threshold condition $\rho+\frac{\delta}{\sigma}>1$ in Section 2 ensured the elasticity with respect to $Y_{t}$ of the expectations term on the right-hand side of (22) exceeded the direct elasticity with respect to $Y_{t}$ of $C_{t}$. The $\rho$ parameter corresponded to the impact of current output on future output, and hence consumption; $\delta$ corresponded to the impact of current output on future inflation, and $\sigma$ (the inverse EIS) in turn determined the impact of inflation expectations on savings.

Section 3.6.2 illustrated that an equivalent qualitative requirement is being met here: lower $Y_{t}$ raises the relative value of saving. But it is helpful to gauge to what extent this is due to the income and substitution channels respectively.

To provide an indicative answer to this, we seek numerical equivalents to the values of $\rho$ and $\delta$ in the current context. Specifically, we analyse numerically the elasticities of $\left[\mathbb{E}_{t}\left[C_{t+1}^{-\sigma}\right]\right]^{-\frac{1}{\sigma}}$ and $\left[\mathbb{E}_{t}\left[\Pi_{t+1}^{-1}\right]\right]^{-\frac{1}{\sigma}}$ with respect to $C_{t}$ - based on a similar off-equilibrium exercise to Section 3.6.2. These elasticities can be associated loosely with $\rho$ and $\frac{\delta}{\sigma}$ respectively, though clearly this is an incomplete decomposition of $\left[\mathbb{E}_{t}\left[C_{t+1}^{-\sigma} \Pi_{t+1}^{-1}\right]\right]^{-\frac{1}{\sigma}}$ (the covariance between future consumption and future inflation provides a further incentive to save that will not be captured).

Figure 5 plots the quantities of interest: the difference in the log of $\left[\mathbb{E}_{t}\left[C_{t+1}^{-\sigma}\right]\right]^{-\frac{1}{\sigma}}$ from its deterministic steady-state value, relative to the corresponding difference in the $\log$ of $C_{t}$ (blue); and the difference in the log of $\left[\mathbb{E}_{t}\left[\Pi_{t+1}^{-1}\right]\right]^{-\frac{1}{\sigma}}$ relative to the log of $C_{t}$ (red). These are plotted against the $\log$ deviation in $C_{t}$ from its steady-state value. ${ }^{13}$

As the figure shows, it is the substitution channel that appears to play a greater role in inducing higher savings in this model. Graphically this follows from the fact that the blue line is uniformly below the red. For every percentage-point fall in $C_{t}$ there is around a 0.77 percentage-point fall in $\left[\mathbb{E}_{t}\left[\Pi_{t+1}^{-1}\right]\right]^{-\frac{1}{\sigma}}$, whilst the fall in $\left[\mathbb{E}_{t}\left[C_{t+1}^{-\sigma}\right]\right]^{-\frac{1}{\sigma}}$ is in the region of 0.42 percentage points. Hence the model is capturing an autoregressive coefficient in $\log$ consumption of around 0.42 , but a much stronger pass-through from current output to future inflation. As the figure shows, these elasticities approximately constant as the

\footnotetext{
${ }^{13}$ That is, the value for $C_{t}$ that obtains in the equilibrium with no binding zero bound, when no recession has hit for a large number of periods.
} 


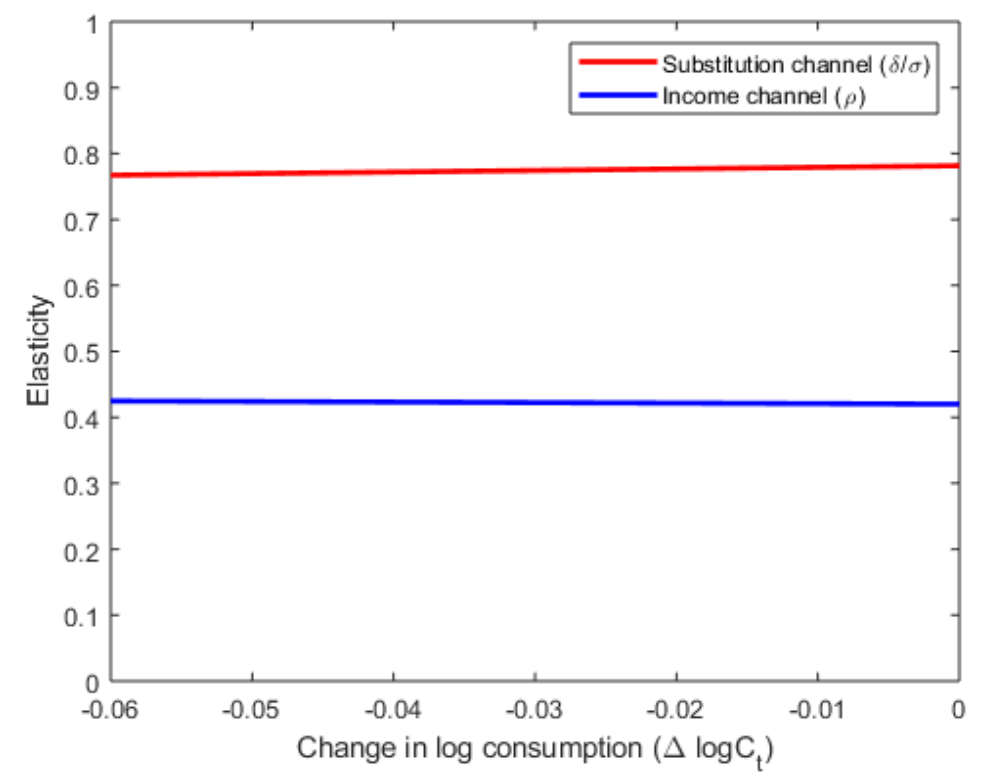

Figure 5: The elasticities of future consumption expectations (in blue) and real interest rate expectations (in red) with respect to current consumption, plotted against different values for the fall in current consumption.

underlying deviation in $C_{t}$ changes.

The importance of inflation expectations in driving consumption at the zero bound remains a source of debate, with some suggestions that observed responses are smaller than policy models assume. ${ }^{14}$ It is clear from Figure 5 that an inflation expectations channel is important to the results of this section, but it should also be clear from the preceding discussion that there is nothing necessary about this. A model with a stronger structural link from current to future income, replacing the inflation expectations channel, would be equally capable of generating multiplicity.

\section{Fiscal policy}

An important focus of the literature on macroeconomic outcomes at the zero bound has been the potential for fiscal policy to mitigate recessions. The influential papers by Christiano, Eichenbaum and Rebelo (2011) and Eggertsson (2011) have shown that the government ex-

\footnotetext{
${ }^{14}$ Contrasting perspectives are provided by Bachmann, Berg and Sims (2015) and D'Acunto, Huang and Weber
} (2018). 
penditure multiplier can be very large in a 'fundamental' liquidity trap - i.e., one that arises due to a negative shock to the natural rate. The main reason for this is that a promise to keep government spending high so long as the liquidity trap lasts - the experiment that the two papers consider - has a positive impact on inflation expectations, and thus stiumulates current spending through an intertemporal substitution channel. ${ }^{15}$ In their benchmark experiment in a model without capital, Christiano et al. find a government expenditure multiplier of 3.7 .

Against this, Mertens and Ravn (2014) have shown that the multiplier is generally less than one in a non-fundamental liquidity trap of the Benhabib, Schmitt-Grohé and Uribe (2001) type. For low persistence in the sunspot process that drives beliefs, they even report the possibility of a negative multipler. But this is limited to a small region of the parameter space, and is not their benchmark case. The reason for the low multiplier is that a confidence trap relies on a large negative output gap in order for deflation to persist. Were output to increase one-for-one with government spending, the result would be reduced deflationary pressure. To offset this, and preserve the high real interest rate that the liquidity trap demands, output must fall back somewhat - ultimately increasing less than one-for-one with government spending.

In this subsection we conduct an identical experiment to Christiano et al. (2011) and Mertens and Ravn (2014), raising government expenditure above $\bar{G}$ for so long as the zero bound remains binding. Provided the increase in government spending is sufficiently small, the effect is to increase the depth of the self-fulfilling recession, by a quantitatively large amount. That is, there is a large negative fiscal multiplier at the margin for our recessionary equilibria. We provide graphical intuition for this result below, clarifying that it does not depend qualitatively on the chosen calibration. In this regard our results are a stronger counterpoint to the conventional finding of large multipliers even than Mertens and Ravn (2014). Rather than small and occasionally negative, our marginal multipliers are consis-

\footnotetext{
${ }^{15}$ Rendahl (2016) shows that with persistent unemployment higher government spending may further boost current consumption in a liquidity trap via an income effect. By keeping workers employed, the government raises expected future earnings, and this increases current consumption.
} 
tently negative, and large.

However there is an important qualification to this. As we show, a sufficiently large fiscal expansion at the zero bound can rule out our low output equilibrium entirely. Intuitively, this happens once the candidate zero bound equilibrium would deliver a value for $Y_{t}$ so low that the zero bound would also be binding at $t+1$, even in the 'normal' equilibrium consistent with $\sigma_{t+1}=0$. Since the zero bound equilibrium is independent of the state and of time, this would imply the zero bound binding indefinitely. Our equilibrium is constructed based on expectations of long-run convergence back to a 'normal' steady state. This would no longer be possible.

\subsection{A large, negative marginal multiplier}

The first exercise we conduct is to increase $\bar{G}$ by 1 per cent of its value when the zero bound binds, equivalent to a spending increase of just 0.25 per cent of steady-state GDP. Figure 6 compares the equilibrium policy functions for output in this case, against the benchmark of no fiscal expansion. We again focus on the limiting case when the probability of $\sigma_{t}=1$ approaches zero, so that consumers effectively anticipate that they will be on the upper, blue policy function with certainty. This policy function is not affected by the change in government spending when the zero bound binds.

The impact of the additional expenditure is to shift the policy function corresponding to the zero bound equilibrium downwards. Conditional on $\sigma_{t}=1$ being drawn, the level of output in the economy is thus lower. The magnitude of the change is, moreover, substantial. Output is lower by well over a full percentage point when the negative shock hits. The multiplier is -5.3, and this just on impact. As discussed at the start of this Section, the existing debate on the size of the zero bound multiplier has principally focused on the question of whether this multiplier is greater than or less than one - and thus whether consumption increases or decreases in response to greater government spending. Small negative multipliers were found to be possible by Mertens and Ravn (2014) in a liquidity trap equilibrium, but only at the extreme end of the range of possible values for their sunspot persistence 


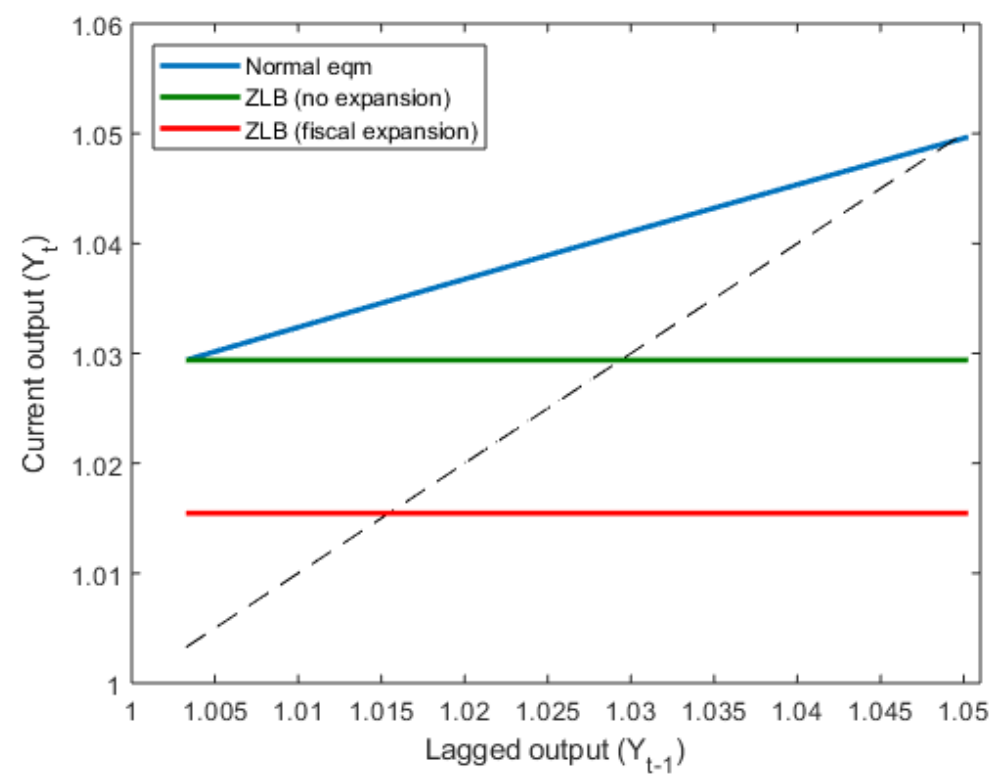

Figure 6: Changes to the model's policy functions when a fiscal expansion of 0.25 per cent of GDP is committed to at the zero bound. The recessionary policy function shifts from the green to the red line in this case, worsening the non-fundamental recession.

parameter - and even then, of a magnitude far smaller than here (-0.2 at most).

Why does this outcome arise? The main intuition can be understood again by reference to the equilibrium consumption-saving decision. Figure 7 plots the marginal rate of substitution between consumption and savings defined in (21), in the benchmark case and with the fiscal expansion. Away from the zero bound the model does not change, and the functions coincide. ${ }^{16}$ At the zero bound, however, higher government spending induces a discrete increase in the relative marginal value of current consumption $C_{t}$ for any given income level $Y_{t}$. The reason for this is straightforward. Product market clearing implies $Y_{t}=C_{t}+G_{t}$, so at each candidate $Y_{t}$ value consumption must fall. Expected outcomes in $t+1$ are entirely unaffected by the choice to use fiscal policy at the ZLB, because the zero bound is expected not to bind with probability 1 thereafter. Thus the only impact on the MRS object:

$$
\frac{C_{t}^{-\sigma}}{\beta\left(1+i_{t}\right) \mathbb{E}_{t} C_{t+1}^{-\sigma} \Pi_{t+1}^{-1}}
$$

at the zero bound is to raise its numerator. It is immediate from the chart that this must

\footnotetext{
${ }^{16}$ The 'fiscal expansion' line is not plotted on this range, as it coincides perfectly with the benchmark case.
} 


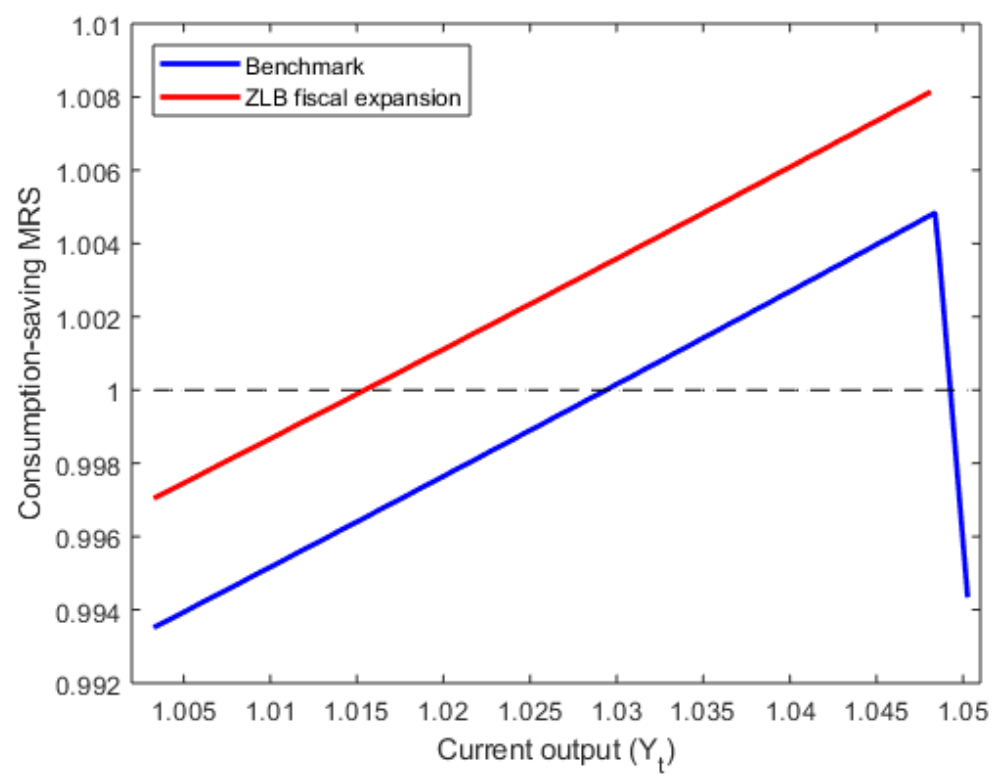

Figure 7: Changes to the plot of the marginal rate of substitution verus $Y_{t}$ as expansionary fiscal policy is used at the ZLB. Current consumption is now relatively more valuable at each $Y_{t}$, but this worsens the recessionary equilibrium.

imply a lower output level, conditional on $\sigma_{t}=1$.

Thus we obtain the apparently paradoxical conclusion that the multiplier is negative at the margin in the recessionary equilibrium precisely because it increases consumers' immediate incentives to spend. Given this, the zero bound outcome can only now arise if the incentives to save are raised by an offsetting amount, and in turn requires the magnitude of the recession to be greater.

\subsection{Non-existence for higher expenditure}

A finding that the marginal fiscal multiplier is negative and large in our zero bound equilibria clearly appears to count against fiscal policy at the zero bound. However, there is an important qualification to this. If the government commits to a sufficiently large expansion in spending once the zero bound binds, the recessionary equilibrium can be ruled out entirely, and the 'normal' outcome becomes the only within-period possibility - given an expectations mapping that is consistent with it.

Figure 8 helps provide intuition for the nonexistence result. For cases where we do have 


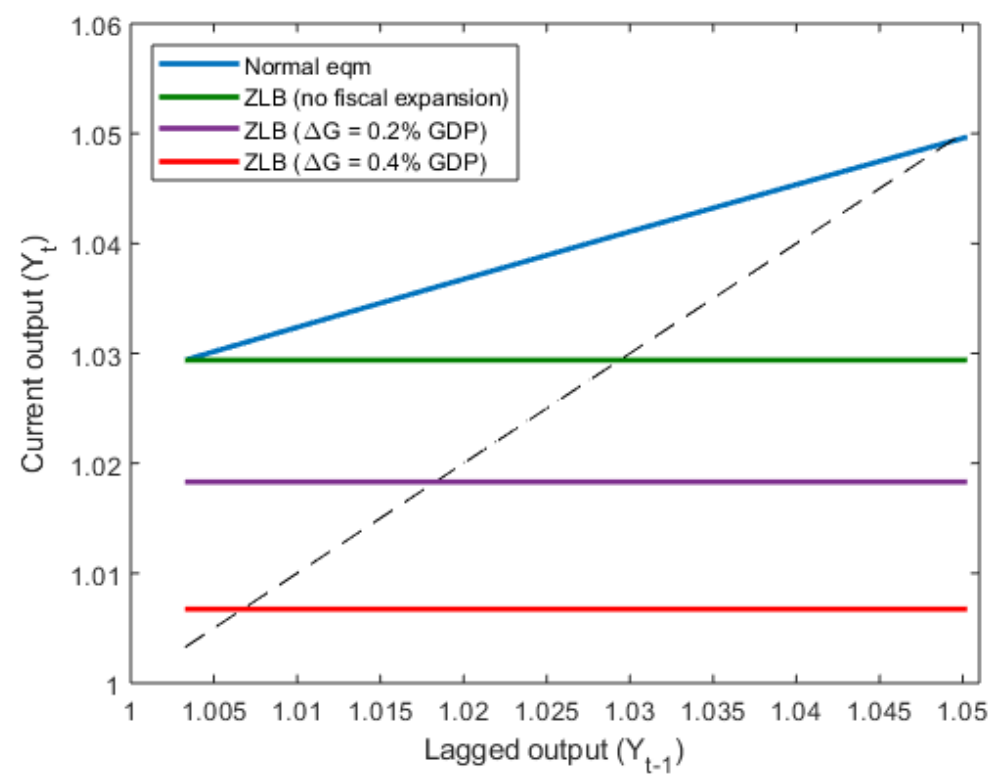

Figure 8: Increases in the fiscal expansion at the ZLB push the recessionary policy function downwards. It must intersect the 45-degree line at a value for $Y_{t-1}$ where the ZLB would not bind in a normal equilibrium. Nonexistence obtains when this is no longer possible.

existence, it shows how the ZLB policy functions for output change as the level of extra government spending at the zero bound increases progressively, from zero to 0.2 and then 0.4 per cent of steady-state GDP. The policy function in the 'normal' equilibrium is also plotted, and is shown to intersect the (green) ZLB policy function with no discretionary spending at the lower end of the range. This occurs at a critical value of $Y_{t-1}$, say $\tilde{Y}$ - roughly 1.003 in the example charted. When $Y_{t}=\tilde{Y}$, the ZLB binds in $t$ regardless of the value of $\sigma_{t}$. For higher values of $Y_{t-1}$, the zero bound does not bind in the normal equilibrium. Recall that the fiscal expansion policy does not affect outcomes away from the zero bound, so the blue policy function is relevant to all three expenditure alternatives.

Comparison with the 45-degree line shows that for all three possibilities, if the recessionary equilibrium arises in period $t$, the implied value of $Y_{t}$ will be consistent with the ZLB not binding in $t+1$ under a normal equilibrium. That is, at the zero bound $Y_{t}>\tilde{Y} .{ }^{17}$ But raising the size of the fiscal expansion brings $Y_{t}$ closer to this critical value.

Now suppose that the recessionary equilibrium were to imply $Y_{t}<\tilde{Y}$. The policy func-

\footnotetext{
${ }^{17}$ Geometrically, the ZLB policy functions intersect the 45-degree line to the right of the intersection between the green and blue functions.
} 
tions are stable over time, so in this case a recessionary equilibrium in $t$ would guarantee that the zero bound would also have to bind in $t+1-$ regardless of realisation of $\sigma_{t+1}$. But since the zero bound outcome is independent of the state $Y_{t}$, if output at the zero bound is below $\tilde{Y}$ in period $t$, the same also must be true in $t+1$. The zero bound would therefore also have to bind in $t+2$, and (by identical logic) in all subsequent periods. In sum, no equilibrium could exist in which the zero bound binds for just a finite number of periods, followed by an exit dynamic of the type charted in Figure 4.

As Benhabib et al. (2001) showed, 'liquidity trap' equilibria in which the economy remains permanently stuck at the zero bound are certainly possible in the environment we consider. But this requires a very different set of expectations from our recessionary episodes. The zero bound policy functions computed for Figure 8 rely on expectations that the economy will return to the conventional zero-inflation steady state in the medium run. These expectations can only be rational if a visit to the zero bound is temporary. Sufficiently high fiscal expenditure at the zero bound makes this feature impossible.

To summarise, the initial question: Which expectations mapping $\phi\left(Y_{t}\right)$ will the economy settle on? is not affected by greater government spending at the zero bound. It is still possible that pessimistic expectations will place the economy in a liquidity trap, and whether this occurs is not the main focus of our paper. But the question: Given $\phi\left(Y_{t}\right)$ consistent with $a$ normal equilibrium, what are the possible outcomes? is affected. A sufficiently large expenditure programme at the zero bound guarantees just one within-period equilibrium, ruling out the recessionary possibility.

\section{Habits and recessionary productivity improvements}

The economy studied in Sections 3 and 4 was deliberately constructed to illustrate the features of our equilibrium in the most straightforward environment possible. The only source of endogenous persistence was the dependence of interest rates on lagged output, through the growth term in the policy rule (15). In this Section we analyse exactly the same type of 
multiplicity problem in an economy with a non-policy-derived, structural source of persistence, namely consumption habits.

Consumption habits are interesting objects of study at the zero bound, because they deliver endogenous changes in the marginal value that consumers place on current versus future consumption. As discussed in the introduction, the bulk of the zero bound literature assumes that the basic disturbance driving interest rates to zero is an increase in the discount factor $\beta$-that is, an exogenous shock to the value of consumption in different periods. With consumption habits, this variability in intertemporal preferences has an endogenous source. The lower consumption was in period $t-1$, the greater is the relative preference for saving in $t$.

As we show, this property can expose economies with consumption habits to non-fundamental recessions at the zero bound. The logic is very similar to the example in Section 3. A fall in output, and thus consumption, in $t$ causes consumers to expect lower consumption demand and lower inflation in $t+1$. At the zero bound, this can be enough to justify the initial fall in output.

Computing an example in which this logic applies enables us to illustrate some potential properties of our equilibria that were not present in Sections 3 and 4, as well as linking what we do to the well-known literature on recessionary productivity improvements. Two general points are worth highlighting. First, we show that in this example equilibrium multiplicity only exists for certain regions of the state space - specifically, when lagged consumption is sufficiently low, such that the zero bound is already binding. In a finding reminiscent of the 'dark corners' that Blanchard (2014) warned against, we thus find that economies at the zero bound may be more susceptible to coordination traps than those away from them.

Second, and related to this, we find that non-fundamental recessionary equilibria can induce multi-period stays at the zero bound. Thus the single-period ZLB episode analysed in Sections 3 and 4 is not indicative of the general possibilities associated with our equilibria.

One way to motivate the economy's initial state falling in the multiplicity region is to incorporate a fundamental stochastic process that will take it there. The simplest example 
is a stochastic process for technology. We allow technology to follow a two-state Markov process, with long periods of high productivity interrupted by occasional, persistent slumps. In this context, we show that the economy is exposed to deep non-fundamental recessions in time periods when productivity has just recovered. These are periods when consumption demand remains low through the habits channel, and the zero bound will be binding in any equilibrium.

This outcome shares many parallels with the idea of recessionary productivity improvements at the zero bound, and the closely connected 'paradox of toil' ${ }^{18}$ As there, the basic setting is one in which fundamental dynamics have driven the economy to the zero bound, at the same time as an improvement in productivity has occurred. However, our emphasis is on the possibility of recessions in this context, not their inevitability. Boneva, Braun and Waki (2016) have recently shown that recessionary productivity improvements will only emerge for a small region of the parameter space, using the conventional equilibrium solution. Wieland (2018) provides parallel empirical grounds for scepticism. Consistent with this, we find that the policy function corresponding to 'normal' equilibrium delivers higher output when productivity increases, except in extreme regions of the state space. By contrast, the region in which multiplicity can occur is much broader.

Overall, we are thus able to provide a contingent defence of recessionary productivity improvements. According to our results, higher productivity can leave the economy exposed to very deep recessions, but coordination on this outcome is by no means inevitable.

\subsection{Setup}

The basic economy that we consider is similar in most aspects to that in Section 3, and we only discuss the changes. The most significant of these is to the consumer utility function,

\footnotetext{
${ }^{18}$ Eggertsson (2010) first expounded the idea of a paradox of toil, whereby an increase in the relative willingness of workers to supply labour could reduce equilibrium employment at the zero bound. In models with simple production structures, including the current, this is isomorphic to an improvement in productivity reducing output.
} 
which now features an external habit term, becoming:

$$
\mathbb{E}_{t} \sum_{s=t}^{\infty} \beta^{s-t}\left[\frac{\left(C_{s}-h \tilde{C}_{s-1}\right)^{1-\sigma}-1}{1-\sigma}-\frac{L_{s}^{1+v}}{1+v}\right]
$$

where $\tilde{C}_{s-1}$ is the average value of consumption across all agents in $s-1$, and $h$ is a parameter reflecting the strength of habits. In equilibrium, $\tilde{C}_{s-1}=C_{s-1}$. This changes conditions (9) and (10) respectively to:

$$
\begin{aligned}
\beta \mathbb{E}_{t}\left[\left(\frac{C_{t+1}-h C_{t}}{C_{t}-h C_{t-1}}\right)^{-\sigma} \frac{\left(1+i_{t}\right)}{\Pi_{t+1}}\right] & =1 \\
\frac{L_{t}^{v}}{\left(C_{t}-h C_{t-1}\right)^{-\sigma}} & =\frac{W_{t}}{P_{t}}
\end{aligned}
$$

and the Phillips curve (12) becomes:

$$
0=(1-\varepsilon)+\varepsilon \frac{W_{t}}{P_{t}}-\Pi_{t} \Theta^{\prime}\left(\Pi_{t}\right)+\beta \mathbb{E}_{t}\left(\frac{C_{t+1}-h C_{t}}{C_{t}-h C_{t-1}}\right)^{-\sigma} \frac{Y_{t+1}}{Y_{t}} \Pi_{t+1} \Theta^{\prime}\left(\Pi_{t+1}\right)
$$

Notice in equation (24) that a reduction in the value of $C_{t-1}$ has a qualitatively similar effect as an increase in $\beta$. Both imply a reduction in the natural real interest rate. Thus, as explained above, consumption habits provide an endogenous route for engineering a 'fundamental' liquidity trap.

The other changes from Sections 3 and 4 are more minor. We include a productivity parameter $A_{t}$ in the production function, so that it becomes:

$$
Y_{t}=A_{t} L_{t}
$$

We set $\alpha_{y}=0$ in the policy rule (15), so that monetary policy is now a conventional feedback rule on inflation alone. Since the focus is no longer on fiscal policy, we also set government spending to zero for simplicity.

The equilibrium definition is unchanged from Section 3.3, subject to these alterations to the model structure. Common parameters are likewise kept at the same values, with the 
exception of $\alpha_{y}$. The habit strength parameter $h$ is set to 0.6. This is not a particularly large value compared to the range considered in the literature, and the main qualitative results are not sensitive to increasing or lowering it at the margin.

The productivity parameter $A_{t}$ follows a two-state Markov process, switching between values of 0.98 and 1 . Conditional on being in the low-productivity state in $t$, the probability of remaining there in $t+1$ is 0.95 . Given the high state in $t$, the probability of remaining in the high state in $t+1$ is 0.99 . This means that the unconditional probability of the high state is $\frac{5}{6}$.

As in Sections 4 and 5, the model is solved by iterating to convergence on an expectations mapping, allowing for an iid sunspot variable $\sigma_{t}$ to resolve within-period multiplicity wherever it emerges. Once more, we graph policy functions for the limiting case in which the equilibrium probability that consumers assign to a non-fundamental recession approaches zero. Because multiplicity only emerges in some regions of the state space, this assumption keeps the policy functions smooth, but qualitative results are again robust to relaxing it. Since income and productivity are sufficient to describe the natural state space, the expectations mapping takes the form $\phi\left(Y_{t}, A_{t}\right)$.

\subsection{Results}

\subsubsection{Multiple policy functions}

Having solved for an equilibrium-consistent expectations mapping $\phi\left(Y_{t}, A_{t}\right)$, in Figure 9 we plot the relevant policy functions for output consistent with this mapping. ${ }^{19}$ When productivity is low, we find just one equilibrium on the range of values for $Y_{t-1}$ plotted. ${ }^{20}$ This corresponds to the green policy function in Figure 9. When productivity is high, either one or two within-period equilibria exist, depending on the value of lagged output. If lagged output was sufficiently high - within around 1.5 per cent of its steady-state value for high

\footnotetext{
${ }^{19}$ The functions have noticeable kinks. These arise as the length of time the economy must stay at the zero bound changes, as a function of the inherited state.

${ }^{20}$ Outside of this range, a standard equilibrium with convergence to the non-deflationary steady state does not exist.
} 


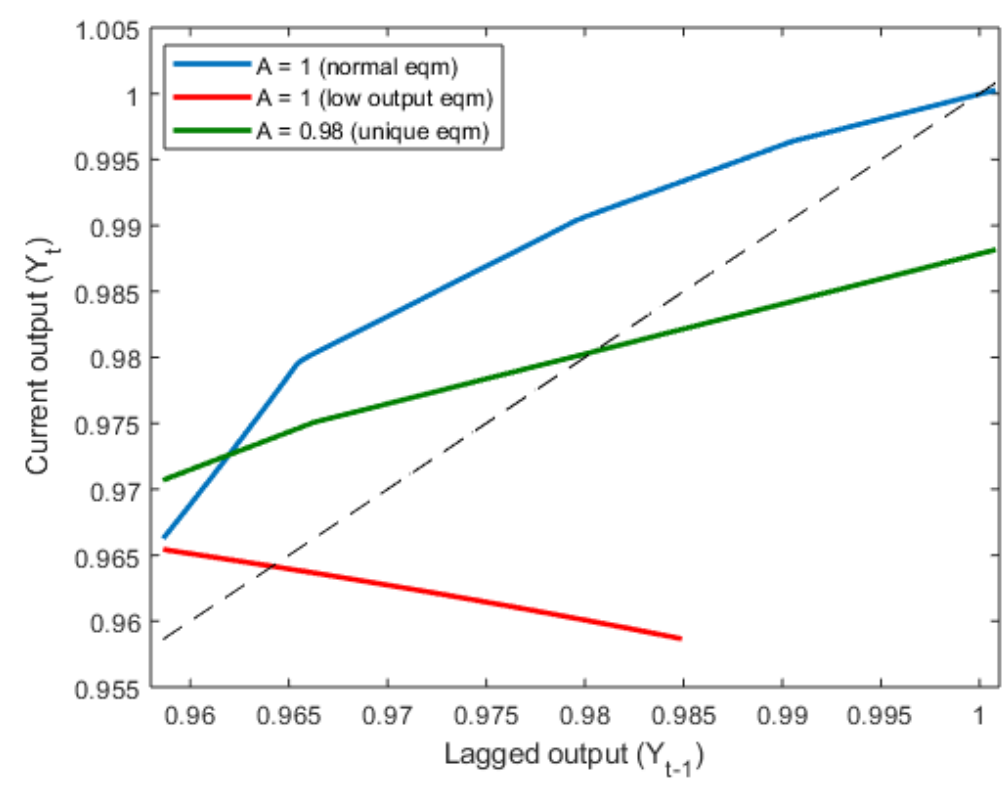

Figure 9: Policy functions for current output $Y_{t}$ as $Y_{t-1}$ varies in the habit model. The green function corresponds to a low productivity draw, whilst the blue and red functions are the multiple possibilities when productivity is high. Multiplicity obtains over a far wider range for $Y_{t-1}$ than the region where productivity improvements are recessionary, neglecting the red policy function.

productivity - then there is a unique high-output equilibrium, traced out by the blue policy function. But if lagged output was sufficiently low, then a low-output equilibrium additionally becomes consistent with the expectations mapping. This is given by the red policy function. It would drive output up to four percentage points lower, and induce a substantially longer stay at the zero bound.

Figure 9 confirms that recessionary productivity improvements are a possible feature of the standard equilibrium concept in this setting. Graphically, when $Y_{t-1}$ is sufficiently low, the green policy function lies above the blue. This means that for these values of $Y_{t-1}$ the short-run implication of an increase in productivity from low to high would be a lower $Y_{t}$ than otherwise. The intuitiuon is as explained in Eggertsson (2010) and elsewhere. Higher productivity reduces expected future inflation in $t$, and this increases the real interest rate by enough to contract aggregate demand - despite the positive income effects of higher productivity. Cuts to the nominal interest rate could offset this channel in principle, but the zero bound prevents this.

Notice, however, that this outcome only emerges when $Y_{t-1}$ is outside of the range that 
could be generated by the productivity shock process alone. If the red policy function is neglected, output is limited to fluctuate in the range bounded by the values where the green

\subsubsection{Discussion}

Two features of the equilibrium multiplicity in this model set it apart from the version studied in Sections 3 and 4. The first is that the mutliplicity problem arises in regions of the state space where the 'normal' equilibrium also sees a binding zero bound on nominal interest rates. That is, rather than one equilibrium with the zero bound binding and one without, here there are two possible outcomes at the zero bound. The second feature is that the multiplicity problem is not universal on the state space.

Both of these properties can be understood by once more plotting the relative marginal value of consumption versus saving for a consumer in a generic time period, as current income varies. Given the habit structure, this is now given by:

$$
\frac{\left(C_{t}-h C_{t-1}\right)^{-\sigma}}{\beta\left(1+i_{t}\right) \mathbb{E}_{t}\left[\left(C_{t+1}-h C_{t}\right)^{-\sigma} \Pi_{t+1}^{-1}\right]}
$$

Figure 10 charts this object, assuming lagged output $Y_{t-1}$ equal to the long-run value that it takes when productivity is low, but a high value for current productivity. Once more, there is a high-output and a low-output equilibrium. As output falls this initially drives up the relative value of current consumption - the direct effect of lower consumption on marginal utility. The greater the reduction in output, however, the more the expectations channel 


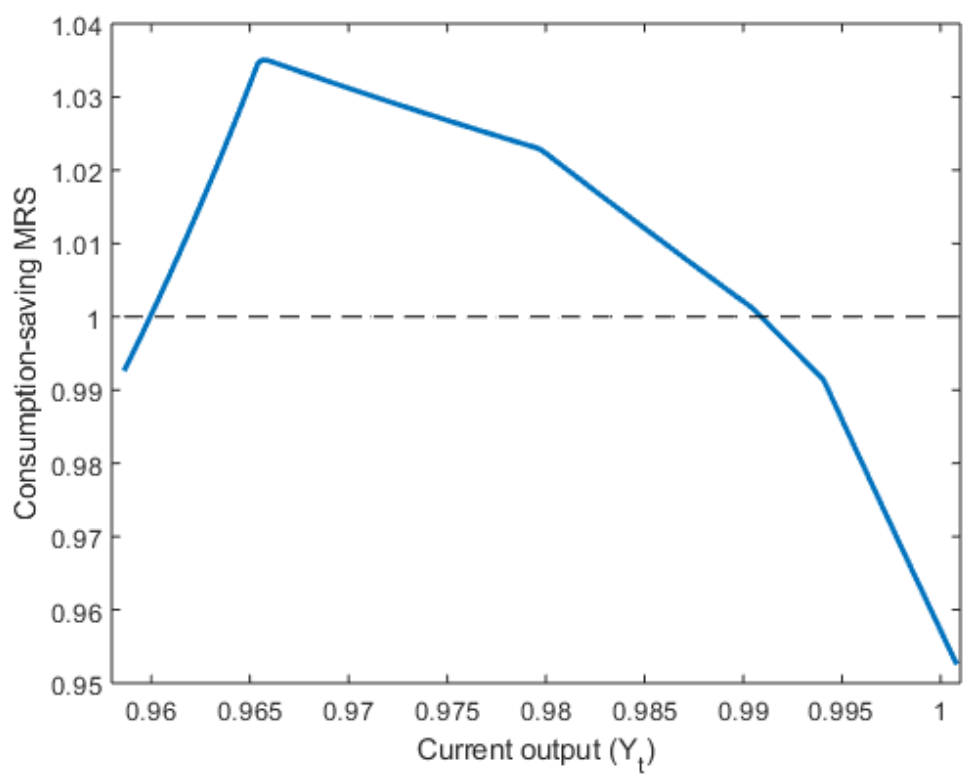

Figure 10: The marginal rate of substitution between consumption and saving as $Y_{t}$ varies in the model with consumption habits. Equilibrium obtains at the two points where the MRS equals one.

comes to matter. Low current output fuels expectations of depressed future conditions, including lower future inflation. Eventually this comes to dominate, allowing a low-output equilibrium to be realised.

The kinks in the schedule in Figure 10 are induced as the length of the economy's expected stay at the zero bound increases. If the recovery from a low-productivity episode involves coordination on the standard, high-output equilibrium, the zero bound is nonetheless binding in $t$, for a single quarter. This is because consumption demand is held down by the habit channel, given low productivity in the past, and this reduces the natural real interest rate.

A low-output equilibrium, by contrast, implies a far longer stay at the zero bound - four quarters for this calibration, assuming no further disturbances. The increased expected length of the zero bound episode worsens expectations of future income and inflation, and this allows low output to be supported in equilibrium. The pessimistic expectations are then justified even if the high-equilibrium outcome is played in all future periods, because an economy with the assumed habit structure will take longer for its natural real interest rate to return to positive territory, given the initial collapse.

Finally, note that a reduction in $Y_{t-1}$, and thus $C_{t-1}$, would cause the schedule in Figure 
10 to shift downwards monotonically, as it reduces the marginal value of consumption in $t$ through the habit channel. It is clear by inspection that this will have the effect of improving the low-output equilibrium and worsening the high-output equilibrium. This intuition is confirmed by the slopes of the respective policy functions in Figure 9.

It is also clear that if $Y_{t-1}$ has fallen sufficiently low, there will not be any equilibrium value of $Y_{t}$ consistent with the rational expectations mapping $\phi\left(Y_{t}, A_{t}\right)$ that we have found. The marginal rate of substitution between consumption and saving would remain below 1 throughout. $^{21}$ In Figure 9 this occurs when $Y_{t-1}$ falls to the left to the point where the red and blue policy functions meet. It is this feature that stops multiplicity from existing at higher values of $Y_{t-1}$. Because $Y_{t}$ is decreasing in $Y_{t-1}$ in the low-output equilibrium, once $Y_{t-1}$ becomes large enough the low-output equilibrium value of $Y_{t}$ would fall so low that equilibrium could no longer exist in $t+1$. Hence the range of the low-output policy function must be limited.

\section{6 (Why) Is this different from BSU (2001)?}

It is well known that multiple non-explosive equilibria exist in dynamic rational expectations models with interest-rate rules, once the zero bound is incorporated. A natural question to ask is how the mechanism in our paper differs from what is already known. In this final brief section before concluding, we explore this issue in more detail.

The 'non-fundamental' liquidity trap was first highlighted by Benhabib, Schmitt-Grohe and Uribe (2001, hereafter BSU), originally making use of an endowment economy with flexible prices. Only the dynamics of the price level and nominal interest rate remain to be determined, with real income and consumption constant over time. In this setting the Euler condition reduces to:

$$
1=\beta\left(1+i_{t}\right) \mathbb{E}_{t} \Pi_{t+1}^{-1}
$$

\footnotetext{
${ }^{21}$ An obvious question is what would happen in these circumstances. Equilibria may still exist with expectations that deliver convergence to a liquidity-trap steady state, or with a time-varying expectations mapping.
} 
The central bank is choosing an interest-rate rule that satisfies the usual Taylor principle, subject to the zero bound:

$$
\left(1+i_{t}\right)=\max \left\{\beta^{-1} \Pi^{*}\left(\frac{\Pi_{t}}{\Pi^{*}}\right)^{\alpha}, 1\right\}
$$

with $\alpha>1$ and $\Pi^{*} \geq 1$. Any path for inflation and the nominal interest rate that satisfies (29) and (30) in all time periods is consistent with equilibrium.

As set out in Section 3, we can describe recursive rational expectations equilibria in this setting by reference to (a) an expectations mapping $\phi$, rationally describing the term $\mathbb{E}_{t} \Pi_{t+1}^{-1}$ as a function of natural state variables in $t$, and (b) a policy function $g$, specifying endogenous variables in $t$ as a function of the inherited state vector from $t-1$ and any relevant coordinating sunspots. ${ }^{22}$ The policy function solves the model's structural equations, given the expectations mapping.

Since the model described by (29) and (30) does not have any state variables, the expectations mapping can take a simple invariant form. In a recursive equilibrium, expectations will be a constant $\phi$, with $\mathbb{E}_{t} \Pi_{t+1}^{-1}=\phi$ for all $t .^{23}$ It is easy to show that two $\phi$ mappings exist that are consistent with rational expectations. One is $\phi=\Pi^{*-1}$, and the other is $\phi=\beta^{-1}$. These correspond directly to the two possible steady-state inflation rates emphasised by BSU (2001).

Now suppose that we fix on the positive-inflation expectations mapping, setting $\phi=$ $\Pi^{*-1}$. As in Sections 3 to 5, we can then investigate the conditional problem: What is the set of policy functions consistent with this mapping? It is trivial to see that there is just one possibility. From equation (29), we have that $\left(1+i_{t}\right)=\beta^{-1} \Pi^{*}$, and this implies $\Pi_{t}=\Pi^{*}$ from (30). Thus current inflation equals expected, consistent with steady state.

The main point is that in the canonical BSU setting, the problem is that there is a multiplicity in the set of expectations mappings. Once expectations are fixed to be consistent with the

\footnotetext{
${ }^{22}$ C.f. equations (16) and (17) above. Time-varying equilibria are also possible: these require time-varying expectations mappings and policy functions.

${ }^{23}$ There will also exist 'non-fundamental' recursive equilibria where $\phi$ varies in $\Pi_{t}$, inducing inflation dynamics in the neighbourhood of the liquidity trap steady state. By the usual determinacy argument, these equilibria cannot be consistent with perfect-foresight convergence to the non-ZLB steady state.
} 
positive-inflation steady state, $\Pi^{*}$ becomes the unique possible inflation rate in the current period too. The concern is that expectations may become trapped elsewhere, but so long as this is avoided, the 'perils' of Taylor rules are averted.

Our paper has focused on an alternative result: there may be multiple policy functions consistent with a given expectations mapping, even when this mapping otherwise implies 'standard' equilibria away from the ZLB in the future (equivalent to $\phi=\Pi^{*-1}$ here). For this sort of multiplicity to exist we need an economy with endogenous states, so that the expectations mapping must depend on current outcomes. This mapping can place certain, or near-certain, probability on convergence to a non-ZLB steady state over a known horizon - that is, it can be the 'desirable' expectations from a BSU perspective. Still, with sufficient endogenous persistence a current recession that takes the economy to the zero bound cannot be ruled out.

As discussed in Mertens and Ravn (2014), it is common to query the relevance of the BSU liquidity trap equilibrium, based on arguments from the learning literature. The object of learning in this literature generally is the $\phi$ mapping. Agents update their perception of the link from current to future outcomes based on present observations. With standard leastsquares learning rules, a $\phi$ mapping that is consistent with the 'desirable' steady state, away from the ZLB, is stable under learning. The $\phi$ corresponding to a liquidity-trap steady state is not.

By contrast, learning cannot be used as a criterion to select among the alternative equilibria that we identify. Our multiplicity is conditional on the expectations mapping. It persists after any learning dynamics have converged.

\section{Conclusion}

The general message from this paper is that macroeconomic models with sufficiently rich propagation mechanisms can exhibit strong, temporary recessionary episodes at the zero bound, without any exogenous impulse. This happens because a collapse in current output 
causes rational agents to expect low future output and low future inflation, which together raise the marginal incentives to save. Without a zero bound the monetary authority would be able to offset this effect by cutting rates, preventing any multiplicity problem. But when there is a zero bound, sufficiently large falls in current output can be supported in equilibrium, with the marginal incentive to save and the marginal incentive to consume just balanced.

As a final point, note that we have focused throughout only on recursive rational expectations equilibria, where expectations are a time-invariant function of the natural state vector alone. This focus is slightly restrictive. Adding persistence or history dependence into the sunspot process that governs equilibrium selection is likely to open up a much greater set of equilibrium possibilities, whilst still allowing for near-perfect-foresight convergence back to a non-deflationary steady state. Exploring equilibria of this type is left for further work.

\section{References}

[1] Arifovic, J., S. Schmitt-Grohé and M. Uribe (2018), 'Learning to live in a liquidity trap', Journal of Economic Dynamics and Control, 89, 120-136.

[2] Aruoba, S.B., P. Cuba-Borda and F. Schorfheide (2018), 'Macroeconomic Dynamics at the ZLB: A Tale of Two Countries', Review of Economic Studies, 85, 87-118.

[3] Bachmann, R., T.O. Berg and E.R. Sims (2015), 'Inflation Expectations and Readiness to Spend: Cross-Sectional Evidence', American Economic Journal: Economic Policy, 7(1), $1-35$.

[4] Benhabib, J., S. Schmitt-Grohé and M. Uribe (2001), 'The Perils of Taylor Rules', Journal of Economic Theory, 96, 40-96.

[5] Blake, A. (2012), 'Determining optimal monetary speed limits', Economics Letters, 116, 269-271. 
[6] Boneva, L.M., R.A. Braun and Y. Waki (2016), 'Some unpleasant properties of loglinearized solutions when the nominal rate is zero', Journal of Monetary Economics, 84, $216-232$.

[7] Christiano, L.J., M. Eichenbaum and S. Rebelo (2011), 'When is the Government Spending Multiplier Large?', Journal of Political Economy, 119, 78-121.

[8] Christiano, L.J., and M. Eichenbaum (2012) , 'Notes on Linear Approximations, Equilibrium Multiplicity and E-learnability in the Analysis of the Zero Lower Bound', Manuscript.

[9] Cochrane, J.H. (2011), 'Determinacy and Identification with Taylor Rules', Journal of Political Economy, 119(3), 565-615.

[10] Cole, H.L., and T.J. Kehoe (2000), 'Self-fulfilling Debt Crises', Review of Economic Studies, $67,91-116$.

[11] D'Acunto, F., D. Hoang and M. Weber (2018), 'The Effect of Unconventional Fiscal Policy on Consumption Expenditure', Manuscript.

[12] Eggertsson, G.B., and M. Woodford (2003), 'The Zero Interest-Rate Bound and Optimal Monetary Policy', Brookings Papers on Economic Activity, 1, 139-211.

[13] Eggertsson, G.B. (2010), 'The Paradox of Toil', Federal Reserve Bank of New York, Staff Report no. 433.

[14] Eggertsson, G.B. (2011), 'What Fiscal Policy is Effective at Zero Interest Rates?', NBER Macroeconomics Annual, 25, 59-112.

[15] Evans, G.W., E. Guse and S. Honkapohja (2008), 'Liquidity Traps, Learning and Stagnation', European Economic Review, 52, 1438-1463.

[16] Evans, G.W., and S. Honkapohja (2001), Learning and Expectations in Macroeconomics, Princeton University Press. 
[17] McCallum, B.T. (2007), 'E-stability vis-a-vis determinacy results for a broad class of linear rational expectations models', Journal of Economic Dynamics and Control, 31,

[18] Mertens, K., and M.O. Ravn (2014), 'Fiscal Policy in an Expectations-Driven Liquidity Trap', Review of Economic Studies, 81(4), 1637-1667.

[19] Orphanides, A. (2001), 'Monetary Policy Rules Based on Real-Time Data', American Economic Review, 91, 964-985.

[20] Orphanides, A. (2003), 'Historical Monetary Policy Analysis and the Taylor Rule', Journal of Monetary Economics, 50, 983-1022.

[21] Orphanides, A., and J.C. Williams (2002), 'Robust Monetary Policy Rules with Unknown Natural Rates', Brookings Papers on Economic Activity, 2:2002, 63-145.

[22] Rendahl, P. (2016), 'Fiscal Policy in an Unemployment Crisis', Review of Economic Studies, 83, 1189-1224.

[23] Smets, F., and R. Wouters (2007), 'Shocks and Frictions in US Business Cycles: A Bayesian DSGE Approach', American Economic Review, 97(3), 586-606.

[24] Stock, J.H., and M.W. Watson, (1999), 'Business cycle fluctuations in us macroeconomic time series', in: J.B. Taylor and M. Woodford (ed.), Handbook of Macroeconomics, ed. 1, vol. 1, chapter $1,3-64$.

[25] Uribe, M. (2018), 'The Neo-Fisher Effect: Econometric Evidence from Empirical and Optimizing Models', NBER Working Paper 25089.

[26] Wieland, J. (2018), 'Are Negative Supply Shocks Expansionary at the Zero Lower Bound?', Journal of Political Economy, forthcoming.

[27] Woodford, M. (2003), Interest and Prices: Foundations of a Theory of Monetary Policy, Princeton: Princeton University Press. 
[28] Woodford, M. (2013), 'Macroeconomic Analysis without the Rational Expectations Hypothesis', Manuscript. 